\title{
Multi-photon microscopy in cardiovascular research
}

Citation for published version (APA):

Wu, Z., Rademakers, T., Kiessling, F., Vogt, M., Westein, E., Weber, C., Megens, R. T. A., \& van Zandvoort, M. (2017). Multi-photon microscopy in cardiovascular research. Methods, 130, 79-89. https://doi.org/10.1016/j.ymeth.2017.04.013

Document status and date:

Published: 01/11/2017

DOI:

10.1016/j.ymeth.2017.04.013

Document Version:

Publisher's PDF, also known as Version of record

Document license:

Taverne

Please check the document version of this publication:

- A submitted manuscript is the version of the article upon submission and before peer-review. There can be important differences between the submitted version and the official published version of record.

People interested in the research are advised to contact the author for the final version of the publication, or visit the DOI to the publisher's website.

- The final author version and the galley proof are versions of the publication after peer review.

- The final published version features the final layout of the paper including the volume, issue and page numbers.

Link to publication

\footnotetext{
General rights rights.

- You may freely distribute the URL identifying the publication in the public portal. please follow below link for the End User Agreement:

www.umlib.nl/taverne-license

Take down policy

If you believe that this document breaches copyright please contact us at:

repository@maastrichtuniversity.nl

providing details and we will investigate your claim.
}

Copyright and moral rights for the publications made accessible in the public portal are retained by the authors and/or other copyright owners and it is a condition of accessing publications that users recognise and abide by the legal requirements associated with these

- Users may download and print one copy of any publication from the public portal for the purpose of private study or research.

- You may not further distribute the material or use it for any profit-making activity or commercial gain

If the publication is distributed under the terms of Article $25 \mathrm{fa}$ of the Dutch Copyright Act, indicated by the "Taverne" license above, 


\title{
Multi-photon microscopy in cardiovascular research
}

\author{
Zhuojun $\mathrm{Wu}^{\mathrm{a}, \mathrm{e}}$, Timo Rademakers ${ }^{\mathrm{b}, \mathrm{c}}$, Fabian Kiessling ${ }^{\mathrm{e}}$, Michael Vogt ${ }^{\mathrm{f}}$, Erik Westein ${ }^{\mathrm{g}}$, \\ Christian Weber ${ }^{\mathrm{d}, \mathrm{h}}$, Remco T.A. Megens ${ }^{\mathrm{d}, \mathrm{h}}$, Marc van Zandvoort ${ }^{\mathrm{a}, \mathrm{b}, *}$
}

\author{
a Institute for Molecular Cardiovascular Research, University Clinic, RWTH-Aachen University, Pauwelsstrasse 30, 52074 Aachen, Germany \\ ${ }^{\mathrm{b}}$ Department of Molecular Cell Biology, School for Cardiovascular Diseases (CARIM), Maastricht University, Universiteitssingel 50, 67229 ER Maastricht, The Netherlands \\ 'Department of Pathology, Maastricht University Medical Centre, P. Debyelaan 25, 6229 HX Maastricht, The Netherlands \\ d Institute of Cardiovascular Prevention, Ludwig Maximillian's University, Pettenkoferstrasse 8a, 80336 Munich, Germany \\ e Institute for Experimental Molecular Imaging, University Clinic, RWTH Aachen University, Pauwelsstrasse 30, 52074 Aachen, Germany \\ ${ }_{\mathrm{f}}^{\mathrm{f}}$ Institute of Laboratory Animal Science and Experimental Surgery, University Clinic, RWTH-Aachen University, Pauwelsstrasse 30, 52074 Aachen, Germany \\ ${ }^{g}$ Atherothrombosis and Vascular Biology, Baker IDI Heart and Diabetes Institute, 75 Commercial Rd, Melbourne 3004, Australia \\ ${ }^{\mathrm{h}}$ School for Cardiovascular Diseases (CARIM), Maastricht University, Universiteitssingel 50, 67229 ER Maastricht, The Netherlands
}

\section{A R T I C L E I N F O}

\section{Article history:}

Received 9 February 2017

Received in revised form 27 March 2017

Accepted 11 April 2017

Available online 18 April 2017

\section{Keywords:}

Optical imaging

Cardiovascular imaging

Carotid artery

Non-linear microscopy

Intravital imaging

\begin{abstract}
A B S T R A C T
Multiphoton laser scanning microscopy has proven profound value for ex vivo 3D histology and in vivo imaging of motionless tissue. The development of triggering systems and fast imaging methods, combined with advanced preparation procedures solved the challenging task of intravital imaging of the fast pulsating heart and major arteries in animals and further increased the popularity of intravital multiphoton imaging in cardiovascular research.

This review article will highlight the potential of multiphoton microscopy for the visualization and characterization of dynamical and structural processes involved in cardiac and vascular diseases, both in an ex vivo and an intravital animal setting. Examples will be given how multiphoton microscopy can be applied to imaging of atherosclerotic plaque development and progression at subcellular level as well as to intravital imaging of inflammatory processes in the heart. In addition to highlighting the potential of multiphoton microscopy in preclinical cardiovascular research, we will discuss how this tool and its applications may be clinically translated to support disease diagnosis and therapy in patients.
\end{abstract}

(c) 2017 Elsevier Inc. All rights reserved.

\section{Contents}

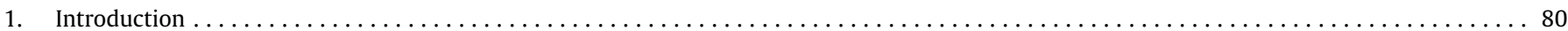

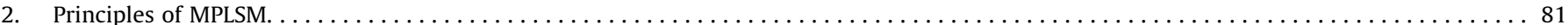

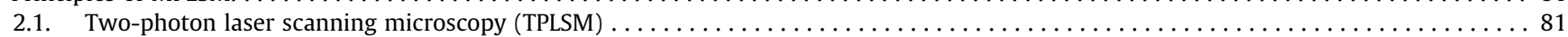

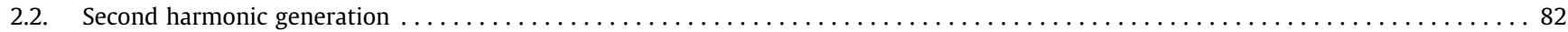

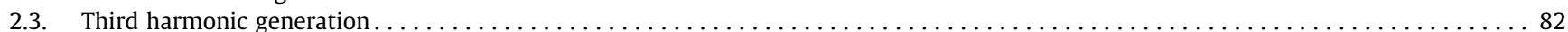

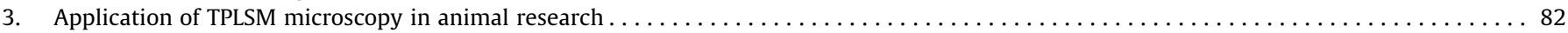

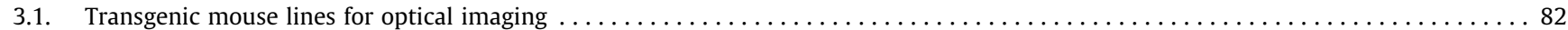

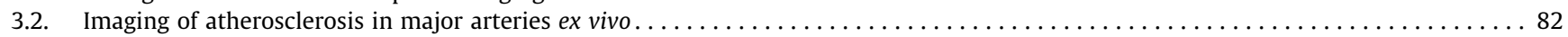

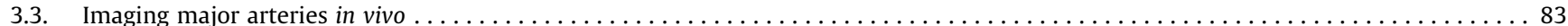

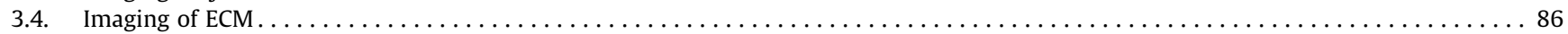

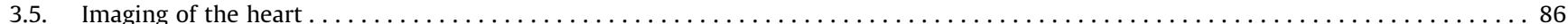

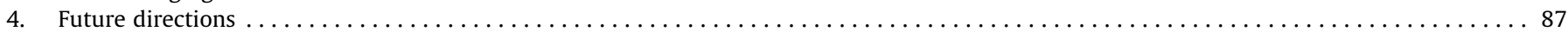

Abbreviations: ApoE, apolipoprotein E; ECM, extracellular matrix; EG, endothelial glycocalyx; GFP, green fluorescent protein; MPLSM NIR, multiphoton laser scanning microscopy; NO, nitric oxide; SHG, second harmonic generation; THG, third harmonic generation; STED, stimulated emission depletion; STORM, stochastic optical reconstruction microscopy; TPLSM, two-photon laser scanning microscopy; YFP, yellow fluorescent protein.

* Corresponding author at: Department of Molecular Cell Biology, School for Cardiovascular Diseases (CARIM), Maastricht University, Universiteitssingel 50, 6229 ER Maastricht, The Netherlands.

E-mail address: mamj.vanzandvoort@maastrichtuniversity.nl (M. van Zandvoort). 


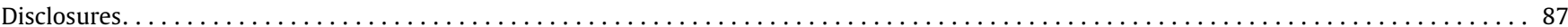

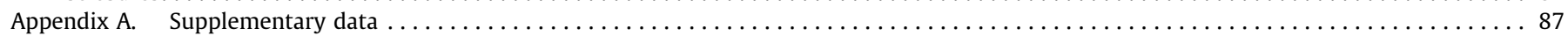

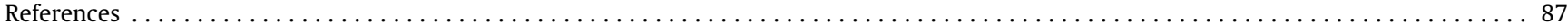

\section{Introduction}

Although death rates from cardiovascular diseases (CVD) have been declining in recent years, they still remain one of the leading causes of morbidity and mortality in Western societies [1]. A significant part of life-threatening cardiovascular events (e.g., myocardial infarction and stroke) is triggered by atherosclerosis of major arteries, characterized by chronic inflammation of the blood vessel wall with resultant accumulation of modified lipoproteins, macrophages, and T-cells. Ultimately, atherosclerosis leads to remodeling of the blood vessel wall due to formation of plaques. On rupture, these lesions cause thrombosis and embolization with consequent blockage of blood flow [2,3]. While atherosclerosis is the most prominent cause, cardiovascular events can also be caused by cardiac malfunctioning on a genetic (e.g., specific types of arrhythmia's), inflammatory (e.g., arrhythmia's, myocarditis, fibrosis), atherosclerotic (e.g., heart failure), or metabolic (such as diabetes) background.

A range of non-invasive animal and clinical imaging technologies, such as magnetic resonance imaging (MRI), computed tomography (CT), nuclear imaging (PET, SPECT), and ultrasound (US), provide detailed anatomical and functional information on the cardiovascular system at micro- to millimeter scale. Additionally, several mesoscopic semi-invasive optical imaging techniques, such as optical coherence tomography (OCT) [4], and photoacoustic tomography (PAT) $[5,6]$, are being used for imaging in animal and human atherosclerosis. The application of these techniques is well-reviewed [7,8], including their limitations regarding sensitivity, resolution, and penetration depth (Fig. 1).
Unfortunately, all these modalities lack spatial resolution to yield information at (sub)cellular level [9], while such information is crucial to improve the understanding of diseases like atherogenesis or cardiac arrhythmia. Such in-depth understanding, in turn, is essential for the development of tailor-made prevention, detection, and intervention strategies. Optical microscopy techniques (see Fig. 1) offer the required spatial resolution and therefore allow not only the detailed assessment of tissue morphology, but also insights into tissue composition and cellular marker expression at molecular level. However, high resolution comes at the price of limited penetration depth in tissue, with invasiveness as a consequence. Traditional confocal microscopy and the upcoming super-resolution nanoscopy (STED, PALM, STORM, GSDIM, SIM) [10] in general focus on the imaging of cellular and subcellular processes in either cell cultures, fixed cells, or thin tissue samples (such as histological slices). As such they have provided scientists with a wealth of information on cellular pathways and distribution of proteins. Also photoacoustic microscopy (PAM) [11], and optical coherence microscopy (OCM) [12], although limited in resolution, have found specific fields of application in cardiovascular research, such as determination of oxygenation of blood in micro-vessels. In this review we will elaborate on multiphoton laser scanning microscopy (MPLSM), a technique that due to its combination of high resolution and high penetration depth has found broad application in ex vivo and in vivo imaging in cardiovascular disease in both basic and translational research.

MPLSM is used to assess cardiovascular diseases ex vivo and in vivo in animals, while in human tissue currently only ex vivo applications are feasible [13-17]. MPLSM overcomes many of the

\begin{tabular}{|c|c|c|c|c|c|c|c|}
\hline $\begin{array}{c}\text { Imaging } \\
\text { modality }\end{array}$ & $\begin{array}{c}\text { Electron } \\
\text { Microscopy } \\
\text { (SEM, TEM) }\end{array}$ & $\begin{array}{c}\text { Optical nanoscopy } \\
\text { (STED, PALM, } \\
\text { STORM) }\end{array}$ & CLSM & TPLSM & OCM/OCT & PAM/PAT & FMT \\
\hline $\begin{array}{c}\text { Lateral } \\
\text { Resolution }\end{array}$ & $1 \mathrm{~nm}$ & $\begin{array}{c}20 \mathrm{~nm} \\
\text { (PALM/STORM) } \\
50 \mathrm{~nm} \text { (STED) }\end{array}$ & $250 \mathrm{~nm}$ & $300 \mathrm{~nm} *$ & $4 \mu \mathrm{m} / 10 \mu \mathrm{m}$ & $\begin{array}{c}5 \mu \mathrm{m} / 5- \\
10 \mu \mathrm{m}\end{array}$ & $\begin{array}{c}1-2 \\
\mathrm{~mm}\end{array}$ \\
\hline $\begin{array}{c}\text { Axial } \\
\text { Resolution }\end{array}$ & - & $\begin{array}{c}100 \mathrm{~nm} \text { (3D STED) } \\
500 \mathrm{~nm} \text { (STED) }\end{array}$ & $500 \mathrm{~nm}$ & $500 \mathrm{~nm} *$ & $2 \mu \mathrm{m} / 1 \mu \mathrm{m}$ & $\begin{array}{c}6 \mu \mathrm{m} / 15 \\
\mu \mathrm{m}\end{array}$ & - \\
\hline $\begin{array}{c}\text { Penetration } \\
\text { Depth }\end{array}$ & - & $20 \mu \mathrm{m}$ & $50 \mu \mathrm{m} * *$ & $\begin{array}{c}500- \\
1000 \\
\mu \mathrm{m} * *\end{array}$ & $1 \mathrm{~cm} / 2 \mathrm{~cm}$ & $\begin{array}{c}20 \mathrm{~mm} / \\
3 \mathrm{~mm}\end{array}$ & $10 \mathrm{~cm}$ \\
\hline
\end{tabular}

nm $\quad$ mm

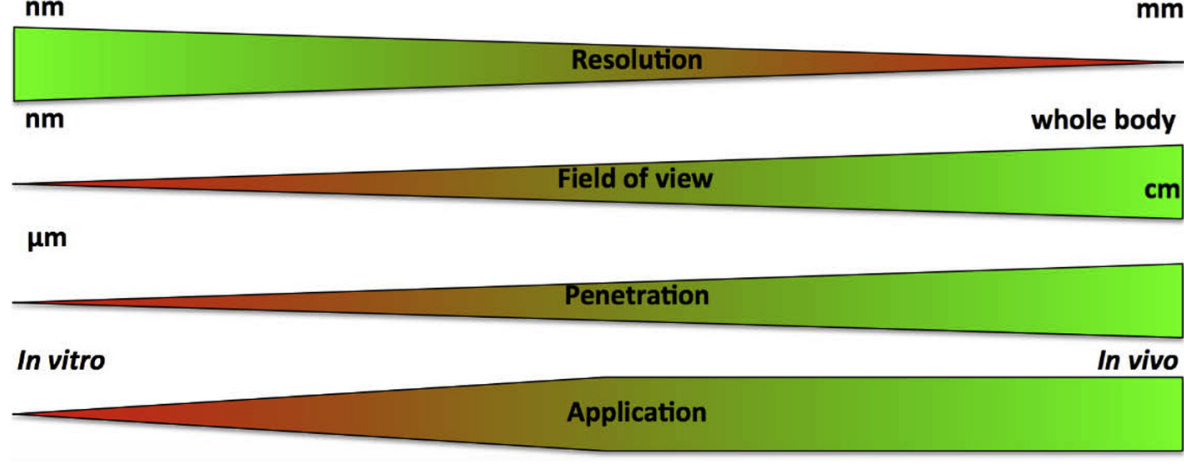

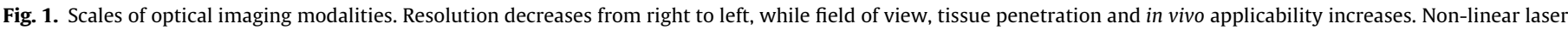
scanning microscopy is an intermediate imaging modality in terms of resolution, FOV, and penetration and therefore serves as bridging modality. 
limitations of conventional single-photon imaging modalities (confocal and widefield fluorescence microscopy), such as image blurriness due to out-of-focus fluorescence, penetration depth of less than $50 \mu \mathrm{m}$, photo-toxicity, photo-activation, and photobleaching $[18,19]$. These are essential advantages in the investigation of the mostly long-term and dynamic cardiovascular disease processes taking place in thick and scattering tissues. Its combination of high spatial resolution in 3 dimensions $(300 \times 300 \times 500 \mathrm{~nm})$ with penetration depth up to $1 \mathrm{~mm}$ (the exact value depending on tissue type) has frequently been used to study intact tissue and provide information thereof at (sub)cellular level [20], such as atherosclerotic plaques [21], blood vessels [18] and hearts [22]. It allows the simultaneous acquisition of functional, structural, and molecular information from intact contracting/dilating vessels, blood flow, and beating hearts, offering the opportunity to study cellular processes, such as leukocytes behavior, in their physiological environment [23], avoiding the artifacts arising during the various steps of tissue processing required for classical histology and immunohistochemistry [24] and providing true 3D tissue architecture. MPLSM therefore provides an important link between basic research and clinical cardiovascular imaging, since it can extend in vitro (cellular) assays and conventional microscopy to mechanistic in vivo animal studies, while on it also can be used for the evaluation of clinical drugs and contrast agents through coupling of a fluorescent dye.

This review will describe the principles of MPLSM and related experimental preparation- and triggering-techniques, especially focusing on imaging of arterial and myocardial inflammation in animals and humans. It will address both the advantages and limitations of its use in cardiovascular research on ex vivo tissue and in vivo, and highlights how its application can support both basic research and, in future, clinical translation.

\section{Principles of MPLSM}

\subsection{Two-photon laser scanning microscopy (TPLSM)}

Linear or single-photon fluorophore excitation, as applied in wide-field and confocal microscopes, is achieved by a laser or LED that emits photons in the visible wavelength region (400$750 \mathrm{~nm}$ ). Fluorescence then arises from fluorophores falling back from their excited state to their ground state (Fig. 2B). In contrast, two-photon excitation requires the fluorophore to absorb within approximately $10^{-18} \mathrm{~s}$ two near-infrared (NIR) photons, each with half the energy necessary for single-photon excitation [25]. As the probability of such an excitation event is extremely low, a high and spatially confined photon density is required. Such densities can only be provided in the focal spot of a powerful femtosecondpulsed laser, incident on the sample through a high numerical aperture lens (Fig. 2A). Consequently, fluorescent photons always originate from the focal spot and all fluorescent photons can be used for detection, independent of their scattering history. Pinholes for removal of out-of-focus fluorescence, essential in confocal microscopy, are not needed.

Although the spatial resolution of confocal microscopy supersedes that of TPLSM at shallow depths [26] (since the wavelength of excitation for TPLSM is significantly longer), due to reduced scattering of the NIR excitation light, TPLSM penetrates deeper into biological tissues without significant loss of resolution. In contrast, in confocal microscopy the pinholes rapidly become less effective with depth due to scattering, and therefore resolution deteriorates rapidly. Although high photon density is needed for two-photon excitation, this high density is only maintained for $80-100$ femtoseconds. Consequently, the average energy output of the NIR laser is much lower than that of continuous lasers, which reduces photo-damage, photo-toxicity, and photo-bleaching. Phototoxicity is further reduced by the use of NIR light and by confinement of absorption to the focal spot, enabling long-term in vivo time-lapse measurements [27]. Finally, due to broadening of two-photon absorption spectra relative to their single-photon counterparts, TPLSM allows the simultaneous excitation of multiple dyes with the same near-infrared excitation wavelength, yielding faster multi-color imaging.

Conventional brightfield and fluorescence intravital microscopes often use CCD cameras for image acquisition, while confocal microscopy and TPLSM are based on point-to-point scanning of the field of view. As a result, the imaging rate in the traditional type of laser scanning microscopes is rather low, maximally 5 frames per second for an image of 512 by 512 pixels, with possible motion artifacts in in vivo imaging studies as a consequence. As with almost all microscopic imaging modalities, the usage of high numerical aperture objectives for achieving subcellular resolution
A

$1 P$

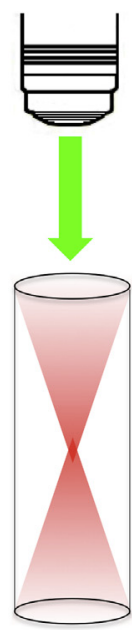

$2 \mathrm{P}$

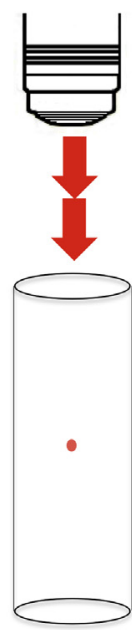

B

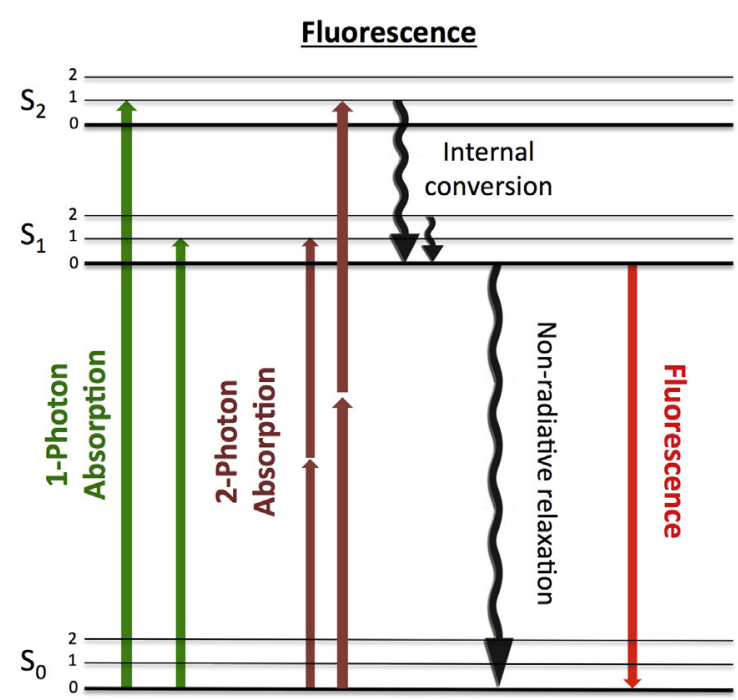

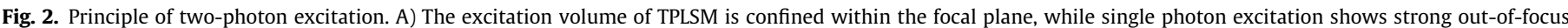

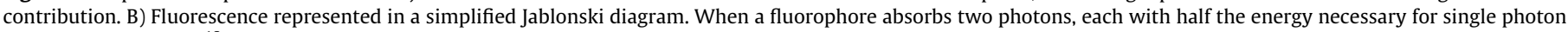
excitation, within $10^{-18} \mathrm{~s}$, two-photon excitation is elicited and fluorescent light will be emitted a few ns later. 
comes at the price of a relative small field of view, e.g. $300 \times 300 \mu \mathrm{m}$. Together with penetration depth up to $1 \mathrm{~mm}$ maximally, this limits the clinical application of microscopic imaging.

It is important to mention that tissue-dependent autofluorescence, although sometimes different than under single-photon excitation, also occurs during two-photon excitation. Autofluorescence often proves helpful in navigating through different layers of tissue, but also might cause problems due to its spectral overlap with the fluorescence of targeted labels.

\subsection{Second harmonic generation}

Another multiphoton process, referred to as second harmonic generation (SHG), is frequently used for label-free imaging of collagen, elastin, and myosin fibers [28]. SHG is a scattering process in which two photons interact simultaneously with a non-centrosymmetric and densly-packed molecule, resulting in the generation of a single photon with exactly twice the energy, i.e. half the wavelength. Consequently, using an incident wavelength of $800 \mathrm{~nm}$ creates a SHG signal at exactly $400 \mathrm{~nm}$ (blue) [29], like in two-photon microscopy at the confined focal spot. Importantly, SHG is a non-absorbing process, thus photo-toxicity and photobleaching are absent. Notably, most of the SHG signal ( 90\%) is scattered in forward direction, yet the backscattered signal, as mostly detected in microscopy set-ups, often is strong enough for imaging of structures at the surface of the tissue. Backward signal from deeper tissue layers is often absorbed or scattered. Although beyond the scope of this review, it is important to note that the forward and backward scattered signals also give different information concerning size of the structures [30]. Biological non-centrosymmetric structures that create SHG are collagen fibers, actin filaments in skeletal muscle fibers, tubulin, and myosin filaments in cardiomyocytes.

\subsection{Third harmonic generation}

Third harmonic generation (THG) is also a scattering process, requiring, however, the simultaneous scattering of three photons to create a single photon at one third of the incident wavelength. As a result, an incident wavelength of $1200 \mathrm{~nm}$ is required for THG imaging at $400 \mathrm{~nm}$. The prerequisite for THG to arise is a sudden change in refractive index, as seen for transitions to certain tissue types, such as neutral lipid depositions, myelin, and specific cellular structures [31,32]. Unfortunately, standard multiphoton microscopes have a limited excitation wavelength spectrum and do not allow THG unless equipped with an Optical Parametric Oscillator (OPO) or fs-pulsed laser in the $1100-1300 \mathrm{~nm}$ range. Therefore, although THG in combination with TPLSM and SHG might prove to be a powerful combination in the future, at the current stage it has not found broad application yet within cardiovascular imaging.

\section{Application of TPLSM microscopy in animal research}

\subsection{Transgenic mouse lines for optical imaging}

The purchase or generation of fluorescent transgenic mouse lines can be a convenient way to ensure fluorescence detection of specific cell subpopulations in an ex vivo or in vivo setup, without the need for complicated labeling protocols. Green fluorescent protein (GFP) is the most commonly used fluorescent reporter [33], but GFP can easily be replaced by any of the fluorescent proteins (e.g., YFP, DsRed, mCherry) available. The GFP-gen inserted into the sequence of constitutively highly expressed proteins such as
$\mathrm{CX}_{3} \mathrm{CR} 1$ induces GFP expression in all blood monocytes [34], while the selective insertion behind the CD11 promoter generates fluorescence only from leukocytes positive for CD11b and CD11c (Table 1). Transgenic mouse lines allow tracking single leukocyte subsets in heart and vasculature using intravital multiphoton microscopy. Particularly interesting for cardiovascular imaging, further cross breeding with $\mathrm{ApoE}^{-1-}$ animals creates the matching background for diet-induced plaque development [35-37].

\subsection{Imaging of atherosclerosis in major arteries ex vivo}

The progression of atherosclerosis is a slow and steady process. Therefore, histologic evaluation of major arteries and cardiovascular tissues at specific time points during disease development in research animals is common routine in atherosclerosis research. Unfortunately, the absence of environmental factors, such as blood pressure and longitudinal tension, during slice preparation causes the blood vessel to collapse and contract, leading to structural and functional alterations $[40,41]$. Imaging of fresh tissue reduces the probability of these artifacts and keeps the 3D structure intact. However, it requires a modality like TPLSM, with its combination of high sensitivity, subcellular resolution, and deep tissue penetration, to visualize and understand the dynamic processes that determine the onset and development of a dense structure like plaque. Imaging of viable blood vessels ex vivo is frequently carried out using perfusion chambers, in which intact isolated vessels are mounted on glass pipettes, pressurized in buffer up to physiological levels, and corrected for longitudinal tension [42]. This procedure preserves vessel wall integrity and keeps them in a physiological environment. Structural and functional vessel wall characteristics can be assessed in 3D optical sections up to several hours after isolation [42]. Specific labeling agents can be applied on mounted arteries either by in vivo administration of labeling agent prior to euthanization and tissue excision, or by ex vivo labeling of mounted arteries extra- and/or intraluminally for improved labeling specificity. Mounting of arteries proved to be an elegant and well-controllable method for investigating the binding and uptake kinetics of for example leukocytes, platelets [43,44], fluorescent US-microbubbles [45], and fluorescent MRI-nanoparticles [46,47] under flow and shear stress conditions.

Arterial walls are composed of three layers, being tunica intima, tunica media, and tunica adventitia (Fig. 3 \& Supplementary video 1). The intima, the layer closest to the lumen, is a relatively thin layer that consists of the basal membrane (mostly collagen IV), covered by a single layer of endothelial cells, in turn covered by the endothelial glycocalyx (EG) $[48,49]$. Reitsma et al. used TPLSM on mounted carotids to study the relation between EG thickness and platelet adhesion during atherogenesis. While in wild type B6 mice, the EG thickness increases with age, no such increase was observed for $\mathrm{ApoE}^{-1-}$ mice. The combination with intravital widefield fluorescence microscopy showed that during atherogenesis platelet adhesion was significantly increased at exactly those locations where EG growth was hampered [13], stressing the athero-protective properties of the EG and the potential of EGreinforcement therapies for the prevention of disease progression.

The intima acts as a semi-permeable barrier controlling migration of cells and proteins into and out of the bloodstream. It has been shown that both the endothelial layer and the EG have antithrombotic, anti-inflammatory, and vasomodulatory functions controlling platelet adherence and activation, and vasodilatation [50] by the secretion of substances such as nitric oxide (NO). Endothelial dysfunction is considered one of the key events in the onset of atherogenesis [13] and therefore is the main target for imaging of early stages of atherosclerosis [13,49]. Using a copper-based fluorescent probe, NO production in carotid arteries 
Table 1

List of transgenic mouse lines commonly used for monocyte tracking.

\begin{tabular}{|c|c|c|c|}
\hline Background & Transgene & Labeled Cell Population & Reference \\
\hline C57BL/6J & CD2-EFGP & GFP expression under the CD2 promotor for CD2, CD3, CD8, TCR beta-chain, NK 1.1 positive cells & [38] \\
\hline C57BL/6J & CD68-EGFP & GFP expression under the human CD68 promotor for CD 11b and CD 115 positive cells & [39] \\
\hline $\mathrm{C} 57 \mathrm{BL} / 6 \mathrm{~J} / \mathrm{ApoE}^{-1-}$ & c-fms-GFP & GFP expression under the c-fms promotor predominantly in CD11a, CD11b, CD14 positive cells & [36] \\
\hline $\mathrm{C} 57 \mathrm{BL} / 6 \mathrm{~J}$ & CX3CR1-GFP & All blood monocytes & [34] \\
\hline $\mathrm{C} 57 \mathrm{BL} / 6 \mathrm{~J} / \mathrm{ApoE}^{-1-}$ & lysM-gfp & GFP expression in correlation with the lysozyme M expression for all mature myelo-monocytic cells & [35] \\
\hline $\mathrm{C} 57 \mathrm{BL} / 6 \mathrm{~J} / \mathrm{ApoE}^{-1-}$ & Itgax-YFP & YFP expression under the CD11c promotor for CD11b and CD 11c positive cells & [37] \\
\hline
\end{tabular}

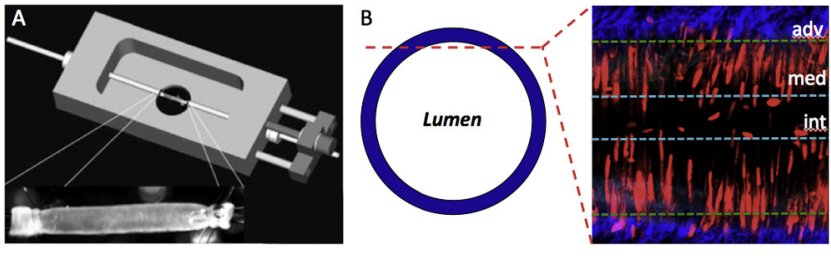

Fig. 3. Ex vivo imaging of explanted mouse carotid arteries. A) Flow chamber displaying a carotid artery mounted on glass pipettes. B) single plane image taken approx. $80 \mu \mathrm{m}$ into the blood vessel, displaying all 3 layers of the vessel: adv $=$ adventitia, med $=$ media, int $=$ intima. Cell nuclei (SYTO71, red) and collagen (SHG, blue) are visible. The position of the image within the lumen is indicated. (For interpretation of the references to colour in this figure legend, the reader is referred to the web version of this article.)

and aortas was directly and specifically visualized [51,52]. Using TPLSM 3D sectioning, it was possible to semi-quantitatively determine NO production in both endothelial and smooth muscle cells, providing valuable information regarding the structural-functional relationship of NO production in the vessel wall. Since altered NO production as a consequence of endothelial dysfunction also results in a number of other cardiovascular symptoms, such as hypertension [53], this opens new avenues for future imaging of structural-functional relationships.

Additionally, the dysfunction of both barrier and secretory functions is accompanied by the luminal presence and release of chemokines and cytokines [54], and overexpression of endothelial cell adhesion molecules, such as intercellular adhesion molecule (ICAM), vascular cell adhesion molecule (VCAM), junctional adhesion molecule A (JAM-A) [55], platelet endothelial cell adhesion molecule (PECAM/CD31), and selectins [56,57]. These processes cause increased accumulation of inflammatory cells, such as monocytes, neutrophils, and T-cells, as well as lipids in the vessel wall. Both cell adhesion molecules and chemokines/cytokines can potentially be used as molecular targets for detection of early stages of lesion development using optical imaging techniques, but since their concentration is expected to be in the nanomolar range they require highly sensitive methods (e.g., antibodycoated fluorescent beads [58]). This especially holds true for targets expressed deeper in the subendothelial space, as most markers will only penetrate these layers to a limited extent. TPLSM has shown its potential as a high-resolution and high-sensitivity imaging method for atherosclerosis in preclinical studies in small animals, both ex vivo and in vivo [14,15,18,23,47] (Fig. 4A \& B) and can furthermore assess distribution and binding of new diagnostic probes and drug carriers at the tissue level. As demonstrated by $\mathrm{Wu}$ et al. and Curaj et al. [59,60], fluorescently labeled ultrasound contrast agents, such as ICAM-1 targeted rhodamineloaded microbubbles, can be used for multimodal imaging of early endothelial inflammation/atherosclerosis. Quantitative analysis of probe binding efficiency, shear stress resistance, and distribution can be performed. Thus, TPLSM can strongly support the development of new molecular imaging probes for clinically applied noninvasive imaging modalities such as ultrasound.

\subsection{Imaging major arteries in vivo}

Leukocyte behavior and function is the key to developing therapeutic strategies for atherosclerosis and myocardial infarction. However, the leukocyte regulatory system is collaborative, hierarchical, competitive, and pervasive at the same time, making the entire system seem maladaptive [61]. Therefore, it is crucial to track leukocytes in large arteries under inflammatory conditions, i.e. during adhesion to, rolling along, and internalization into the vessel wall $[14,36,62,63]$, but also to follow their behavior inside the atherosclerotic lesion. Monocyte-derived macrophages play a key role in both early and late stages of plaque growth, however, it is still not fully understood how lipid loading by macrophages affects their biology and promotes atherosclerosis [64]. While monocyte recruitment and internalization can be studied in vitro and ex vivo, the majority of observations in in vitro studies shows significant differences to their in vivo behavior with respect to subendothelial differentiation [65].

Most conventional (brightfield or fluorescence widefield) intravital setups employ single channel high-speed CCD cameras, which can detect platelets, monocytes, and macrophages, however lack the ability to simultaneously visualize multiple fluorophores or structural details of the vessel wall. Furthermore, due to their limited tissue penetration, they do not allow the observation of platelets and leukocytes through the vessel wall of major arteries. Conclusively, intravital TPLSM imaging of transgenic mouse models utilizing fluorescent protein-tagged leukocyte sub-populations already provided crucial insights on the dynamic mechanisms of recruitment, adherence and transmigration and has the potential to further close the gap between in vitro and preclinical settings.

Initial in vivo studies of the macro- and microvasculature focused mainly on coping with motional artifacts while imaging the vessel wall [23] and leukocyte interactions with the endothelium $[14,15]$. The in vivo motional artifacts are mainly caused by both the cardiac and respiratory cycle of living tissue, which results in movement of tissue beds with a specific frequency. In case of mice, the heart frequency is $5-8 \mathrm{~Hz}$, while the respiratory cycle is $2-4 \mathrm{~Hz}$ (depending on applied anesthesia). Consequently, the major arteries in the thoracic region will display rhythmic motion with similar frequencies and imaging of these tissue beds in vivo with rather slow classical laser scanning microscopes (with $512 \times 512$ frame rates of at best $5 \mathrm{~Hz}$ ) strongly suffers from both intra-frame and inter-frame artifacts. The intra-frame motional artifacts are a result of the laser scanning properties of TPLSM, where there is significant delay between the first scanned pixel in the left top corner of the image matrix and the last scanned pixel at the right bottom corner. As such, the tissue present in the 1$3 \mu \mathrm{m}$ thin focal plane during the single image formation changes, causing deterioration of the image due to loss of focus (Fig. 5) [23]. The inter-frame artifacts in an imaging sequence (either in depth or over time) are caused by the disagreement of tissue in focus between subsequent images. As a result, (three dimensional) reconstructions of cellular processes or structures in vivo are almost impossible to perform without adapting the current imaging methods in order to reduce the impact of motional artifacts. 

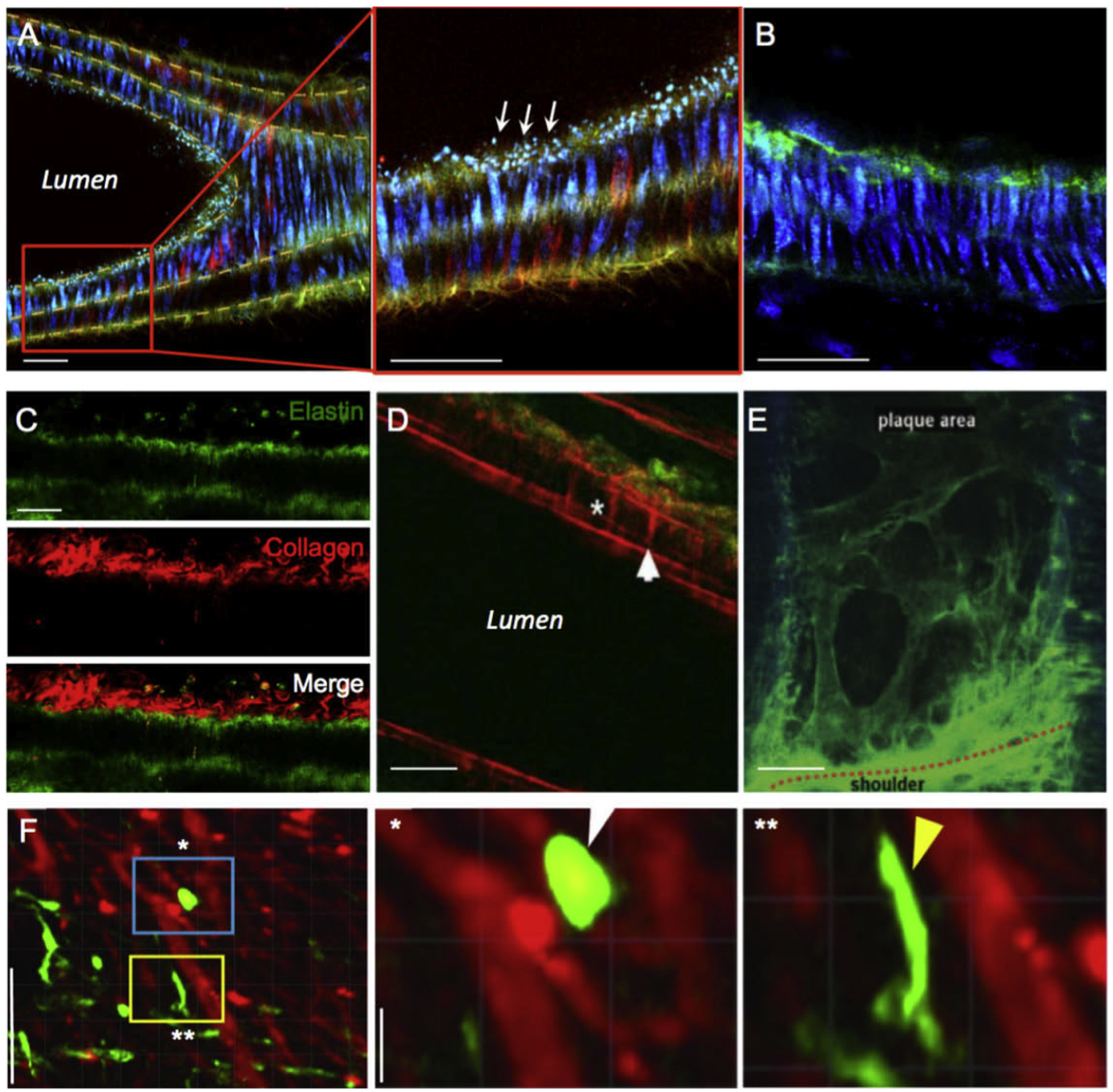

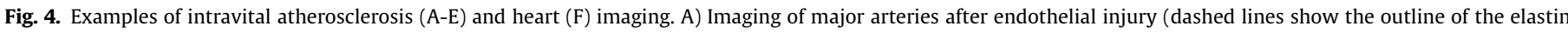

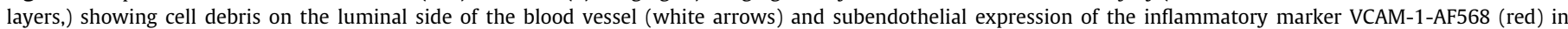

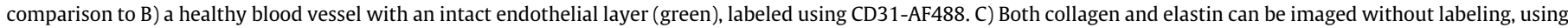

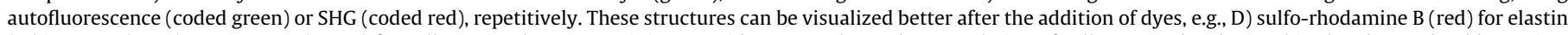

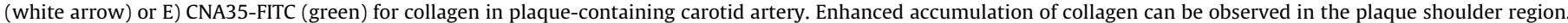

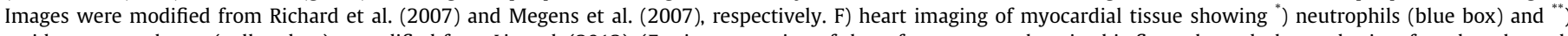

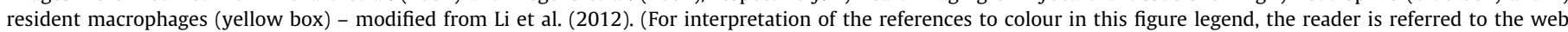
version of this article.)

To achieve this, first attempts tried to stabilize blood vessels using common embedding materials such as agarose. These attempts have not been successful since no significant motion suppression could be achieved. Besides sometimes rather nonphysiological procedures for physical suppression of tissue motion, either by adapting the surgical preparation method [66] or by temporary reduction of the heart rate or respiration [67], there are two other strategies to (partially) overcome intra- and inter-frame artifacts. The first uses triggered acquisition by using the cardiac and respiratory signals, a technique frequently applied in other imaging modalities such as MRI [68]. The second applies faster and continuous scanning of moving tissue randomly and applying extensive post-processing of the image series to detect comparable tissue representations over time. The choice for one of the two depends on the research question at hand. In general, the quality of both methods regarding in vivo image series strongly depends on stability of sample preparation (i.e. tissue drifts or loss of immersion water may cause a shift of the in-focus tissue) and the physiological stability of the animal (mainly depending on anaesthesia, and body temperature).

As an example of the first method, Megens et al. [21] initially utilized a trigger box originally designed for MRI on small laboratory animals (Rapid biomedical, Würzburg, Germany) combined with image acquisition at a rate of $5-6 \mathrm{~Hz}$. This method resulted in stable image series of murine carotid and renal arteries over time without large intra- and inter-image artifacts, however at the costs of overall time resolution. In order to achieve the required acquisition rates and the detection sensitivity, the number of pixels had to be lowered and the scan speed increased. As a result, the image quality suffered due to a degraded signal-to-noise ratio and reduced resolution (Fig. 6). More recently, Chèvre et al. developed a method for vessel stabilization by carefully lifting the artery from the surrounding tissue using a thin metal plate without significantly altering the flow characteristics [36]. Additional motion suppression was achieved by covering the artery with a coverslip. The combination of physical tissue stabilization with different 


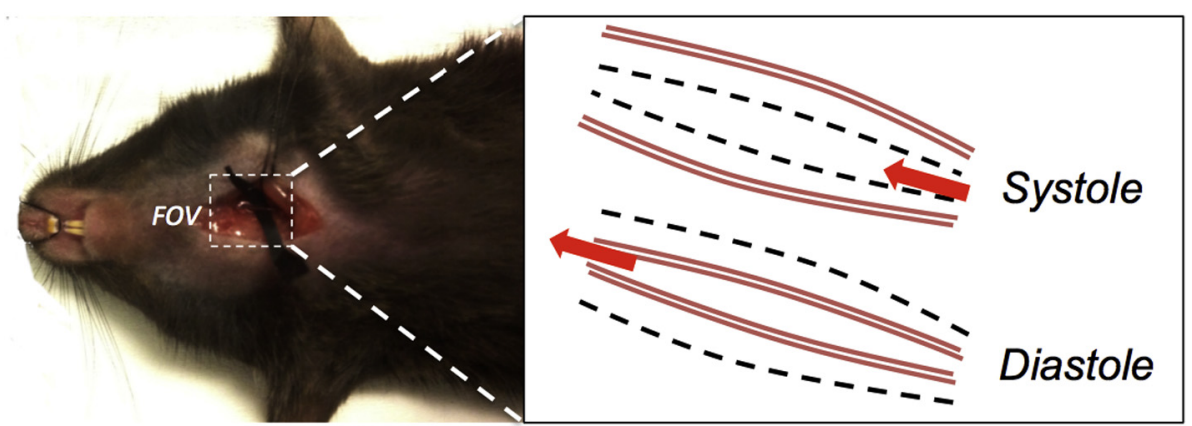

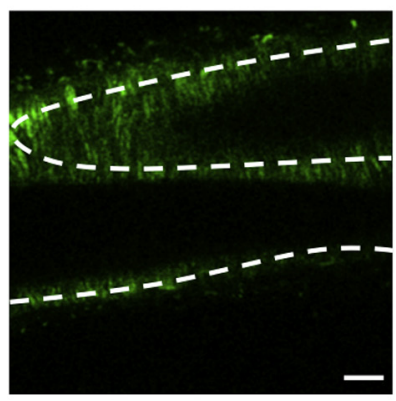

Intrasystole/Intradiastole

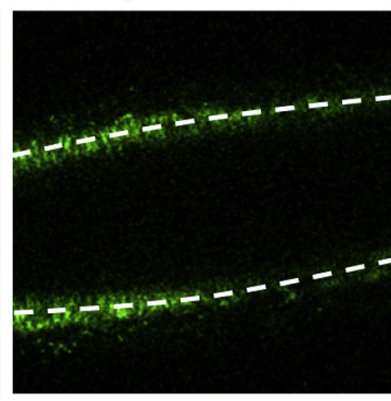

Systole

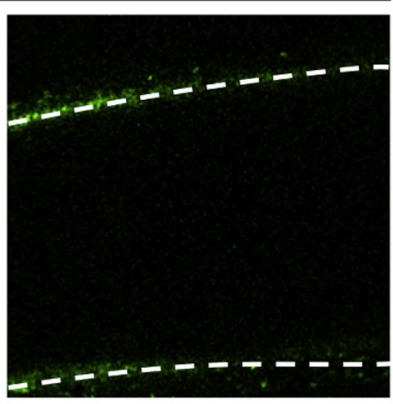

Diastole

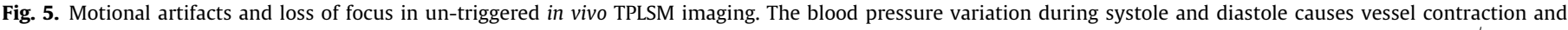

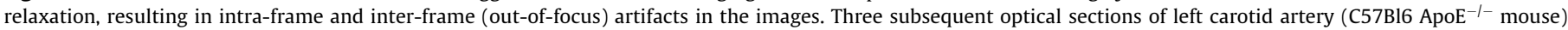

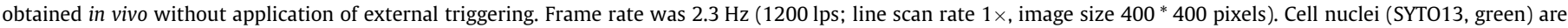

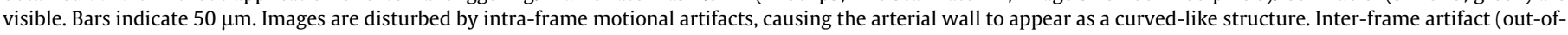

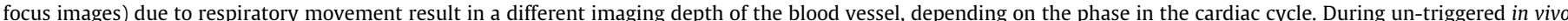

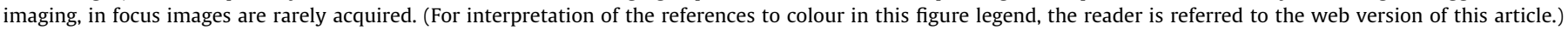

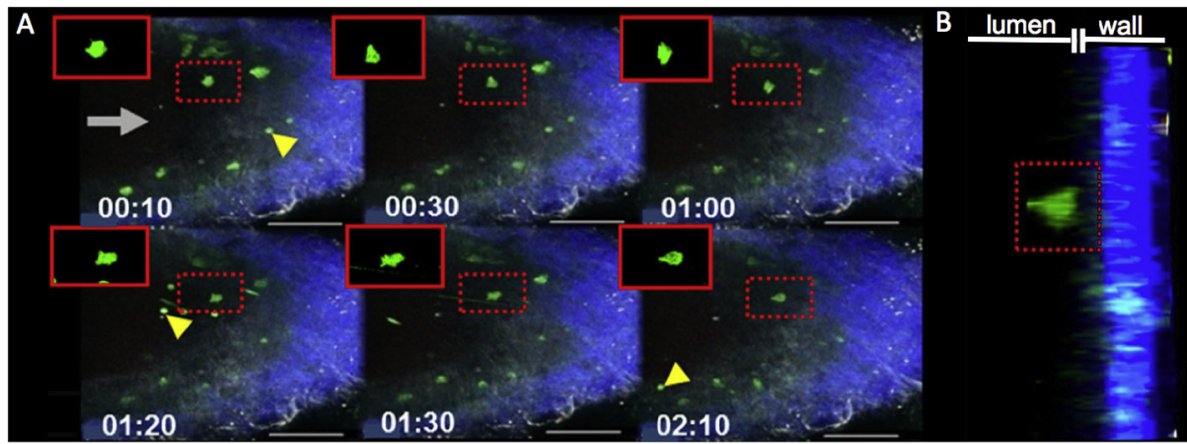

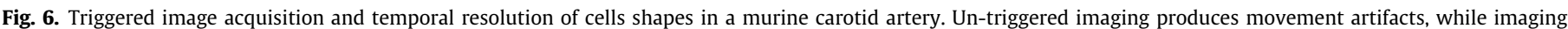

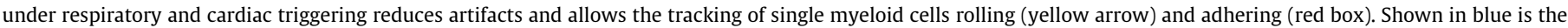

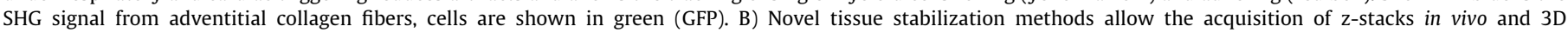

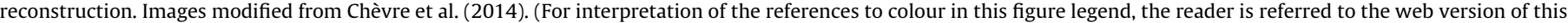
article.)

strategies of controlled image acquisition via triggering, enabled the acquisition of 3D image stacks with relatively high frequency ( $0.1-0.3 \mathrm{~Hz}$ per z-stack) for longer time periods (>30 min) and showed the feasibility of 3D tracking of cells and their function in atherosclerosis-prone arteries in vivo.

The second method is mostly urged by the latest generation of commercially available TPLSM systems. In these systems, overall sensitivity has drastically improved due to strongly improved optics (apochromatic objectives with high numerical aperture and low magnification) and detectors (hybrid detectors). Moreover, the continuous development of novel fluorophores with improved quantum yield and stokes-shift contributes to improvement of image quality [69]. As a consequence, the acquisition times can be shortened, resulting in a strong reduction of the intra- and inter-image artifacts. These set-ups allow acquisition rates of
$>30 \mathrm{~Hz}$ using resonance scanning $(8000-12,000 \mathrm{~Hz}$, [70]) or multiplication of the excitation laser beam (1-64 beams [71,72]), enabling recording at video rate without significant negative impact on the overall image quality, field of view, or resolution. The resultant dataset consists of optical slices captured with a frequency that by far exceeds the frequency of heart beat and respiration (Fig. 6). Such datasets can be subjected to (sometimes extensive) post-processing to detect matching tissue sections over time. In most cases the (partially) undistorted images have a rhythmic appearance (dependent on motion and acquisition frequency) within the data set, which is beneficial for the selection process. As a result of non-triggered imaging, a high number of recorded images can be selected according to their respective motion and imaging depth, producing multiple stacks of data out of one image set. By exploiting an angular difference between the imaging focal 


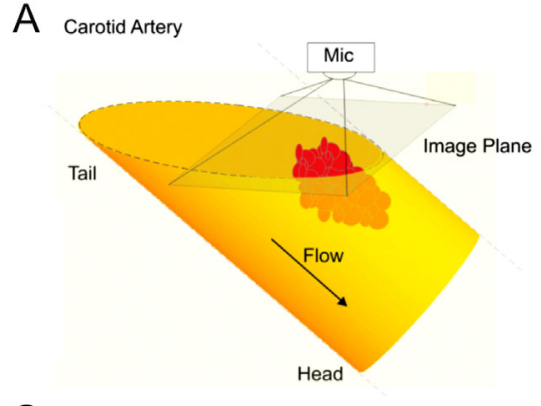

C

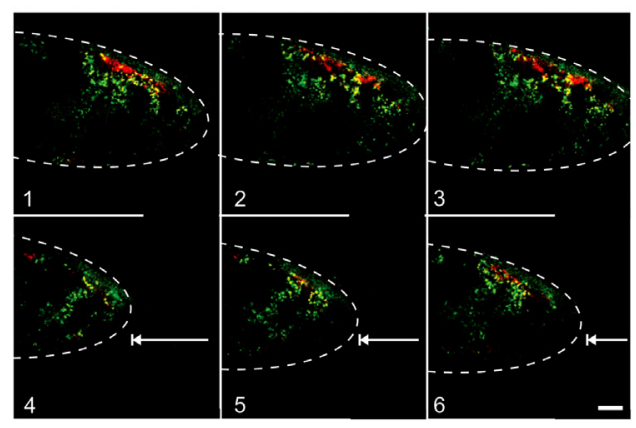

B
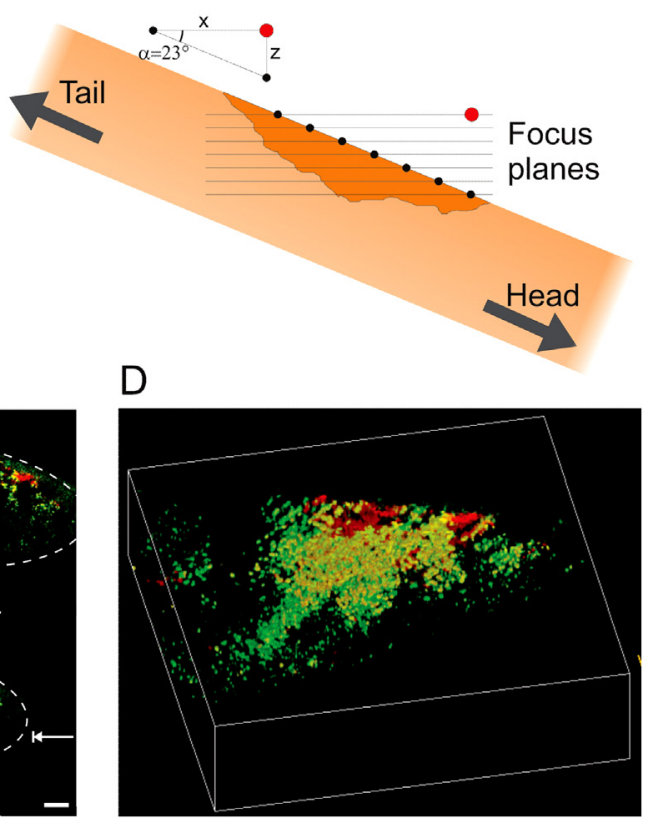

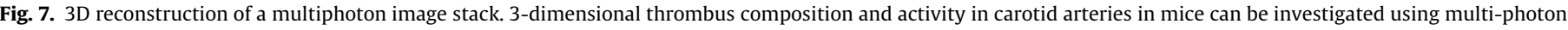

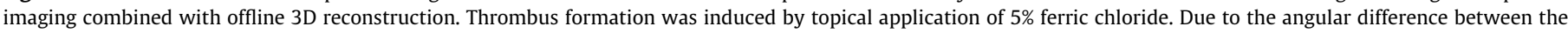

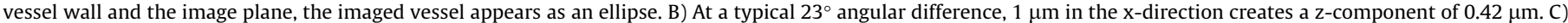

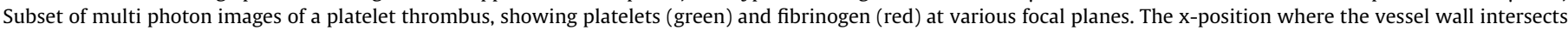

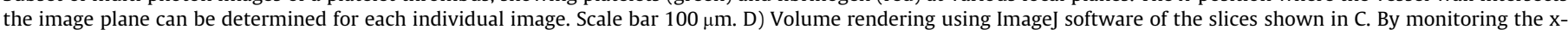

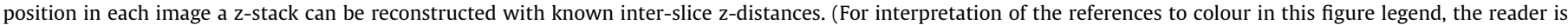
referred to the web version of this article.)

plane and the vessel of interest, a pseudo 3D reconstruction can be performed on a high speed acquisition dataset (Fig. 7 and Supplementary video 2). Secondly, non-moving structures or cells within the selected images may be matched using overlays, edge detection, or co-localization protocols. The matched images may then be used for visualization of biological structures [15] or cell recruitment [14,73]. Post-processing (preferably automated) of the acquired data may be further optimized by making use of the signal recordings of the motion disturbances, e.g. electrocardiography or respiratory signals.

\subsection{Imaging of $E C M$}

In addition to the molecular and functional imaging possibilities described above, TPLSM has become a popular imaging modality for structural visualization of the extracellular matrix components of vessel walls, e.g., elastin in the tunica media or collagen in the tunica adventitia [74]. During lesion progression, the vessel wall undergoes structural remodeling, such as increase of intimamedia thickness (IMT), alteration of EG thickness [13,49], increased smooth muscle cell proliferation, increased collagen synthesis, and increased vasa vasorum in the tunica adventitia [73].

The tunica adventitia of large blood vessels contains large amounts of various types of collagen, responsible for vascular integrity, (age-related changes in) vascular stiffness, hypertension, and plaque stability $[75,76,30-32]$. Its extensive contribution to and impact on vascular remodeling and plaque development has been reviewed by Adiguzel et al. in 2009 [77]. Collagen has been the focus of many cardiovascular-related studies using multiphoton microscopy $[21,78-80]$ because of multiphoton tissue penetration into the deeper vessel layers, label-free collagen imaging using SHG, and because collagen is an essential factor during cardiovascular disease progression (Figs. 3B \& 4C) [81].
The complex mechanisms and dysfunctional balance of collagen synthesis and degradation during atherogenesis has a major impact on disease progression. Collagen content can spike up to $60 \%$ of total plaque proteins, therefore contributing significantly to plaque growth and arterial narrowing in fibrous lesions. Alternatively, collagen degradation in the fibrous cap renders the plaque vulnerable and prone to rupture. It should be noted, however, that only specific types of collagen such as collagen I, III, IV, V, and VIII, along the subendothelial layer are actively involved in plaque development and rupture [77,82]. Also, SHG detection is more difficult deeper in the tissue since SHG is mainly forward scattered and as such backward (epifluorescence) detection is not efficient. This creates the need for collagen specific dyes, as demonstrated in a study by Megens et al. in 2007, where the collagen-marker CNA35 [83] was characterized and established as a molecular marker for atherosclerotic plaques in $\mathrm{ApoE}^{-1-}$ mice [21]. Due to characteristic increase of endothelial permeability and elevated collagen content in lesion areas, CNA35 showed significantly higher binding in lesions compared to healthy tissue (Fig. 4 E).

Other extracellular matrix (ECM)-related proteins, such as elastin and endothelial fibrin $[21,84,85]$, could serve as markers for studying atherosclerotic cap formation and cap thinning. Elastin can be visualized both with auto-fluorescence and exogeneous staining (e.g. using Sulfo-rhodamine B or Eosin, Fig. 4 A, C, and D). It has been shown by Lilledahl et al. that solely based on the elastin/collagen ratio, atherosclerotic plaques can specifically be identified [86,87].

\subsection{Imaging of the heart}

Myocardial inflammation and ischemia can be considered precursors to clinical symptoms and complications which are intensely investigated in vivo at macroscopic resolution levels using 
non-invasive techniques [88]. Mechanistic studies on arrhythmia and inflammation are often conducted in vitro on cell cultures or ex vivo on tissue slices [89,90]. Previously, TPLSM has been involved in some of these studies on ex vivo slabs of cardiac tissue $[88,91,92]$ or ex vivo Langendorff-perfused hearts [93-96]. Even more so, intravital heart imaging with subcellular resolution has been very limited, but has been gaining interest due to technological advances in video rate microscopes, triggering systems, and innovative tissue preparation methods. Yet, the heart is more affected by severe motional artifacts than any other organ, and as such it is still one of the most challenging organs to apply in vivo two-photon microscopy to. In order to (partially) overcome in vivo motional artifacts, timing of the image acquisition between the tissue movements is a logical step. When image acquisition frequency is significantly higher than motional frequency, one can record a single image without intra-image disturbances. Additionally, when motional frequency is very stable and acquisition frequency is high enough, it will be possible to overcome interimage disturbances and as a result studying of structures and/or processes in 3D over time becomes feasible. This was for example demonstrated for intravital and confocal imaging of the lung [97]. By mechanically controlling the respiration, a stable respiration motional frequency was obtained that allowed image acquisition in between the respiration frequency without intra-image artifacts.

Only recently, first attempts have been made to visualize a beating mouse heart in vivo at subcellular resolution. Li et al. used a model involving heterotopic transplants and an imaging chamber [98,22] (Fig. 4 F) to study the migration and extravasation of monocytes into inflamed coronary blood vessels and cardiac tissue over a time period of $3 \mathrm{~h}$. In vivo TPLSM allowed tracking of single cells and quantification of leukocyte migration parameters, such as rolling velocities, crawling velocities, and displacement directionality after extravasation. In vivo imaging of the heart has been further refined by Lee et al. [99], who elegantly combined existing triggering methods with a heart-stabilizing tool that suppresses part of the motion of the beating heart inside the pericardial cavity. The impressive result is high resolution imaging of the intact in vivo mouse heart over several hours, during which endothelial leukocyte recruitment and tracking of monocytes in the beating heart was achieved. Most recently, Lee \& Weissleder et al. developed a new two-photon method for intravital visualization of murine heart at subcellular resolution, quantifying myocyte contraction, arrhythmia, and ischemic injury [100].

These studies exemplify that in vivo heart studies are indeed feasible and open new avenues for various research areas, such as cardiac fibrosis, angiogenesis, valve malfunction, and arrhythmia, also areas where fibrosis plays an important role and the possibility of collagen imaging comes into play [88,101-104].

\section{Future directions}

Although the feasibility of MPLSM in in vivo applications for cardiovascular research has been demonstrated in animals, there have been no reports on its application in humans. Until now, clinical multiphoton microscopic (i.e., two-photon, SHG, and Coherent Anti-Stokes Raman) imaging has almost exclusively been used on human skin, both ex vivo and in vivo [105-107]. Due to limited light penetration through the skin, in vivo cardiovascular multiphoton imaging requires procedures either to expose the tissue of interest to create a surgically embedded optical window or the application of an endoscope.

As already developed and established a decade ago, the combination of (confocal) fluorescence imaging and endoscopy offers the possibility of non- or minimal invasive imaging in humans [108]. Commercial confocal endoscopes, although with more limited res- olution than confocal microscopes, are available and have for example been used for detection of tumors in the gastrointestinal tract or lung [109-112]. Contradictory to the increasing usage of single-photon confocal endoscopy studies in humans in clinical routine, there has been only one TPLSM endoscopy study in humans [113]. The major challenges are the efficient delivery of femtosecond excitation light without major pulse deformation, the wide-field collection of multiphoton fluorescence, and the miniaturization of objective lenses endoscope. Recent technological innovations in photonic crystal fibers [114] and imaging lenses (fiber-coupled gradient-index - GRIN lenses) [115] have partially overcome these limitations. Several multiphoton endoscopes have been developed and tested in animal studies [116,117]. Recent advances, applying the combination of super-resolution and twophoton microscopy have further advanced this field by increasing the resolution to subcellular level [118]. This will most likely contribute to the development of clinical multiphoton endoscope prototypes, potentiating clinical studies outside of the dermatological field in the next years.

\section{Disclosures}

None.

\section{Appendix A. Supplementary data}

Supplementary data associated with this article can be found, in the online version, at http://dx.doi.org/10.1016/j.ymeth.2017.04. 013.

\section{References}

[1] V.L. Roger, A.S. Go, D.M. Lloyd-Jones, E.J. Benjamin, J.D. Berry, W.B. Borden, D. M. Bravata, S. Dai, E.S. Ford, C.S. Fox, H.J. Fullerton, C. Gillespie, S.M. Hailpern, J.A. Heit, V.J. Howard, B.M. Kissela, S.J. Kittner, D.T. Lackland, J.H. Lichtman, L. D. Lisabeth, et al., Executive summary: heart disease and stroke statistics2012 update: a report from the American Heart Association, Circulation 125 (1) (2012) 188-197.

[2] R. Ross, Atherosclerosis-an inflammatory disease, N. Engl. J. Med. 340 (2) (1999) 115-126.

[3] A.C. van der Wal, A.E. Becker, Atherosclerotic plaque rupture-pathologic basis of plaque stability and instability, Cardiovasc. Res. 41 (2) (1999) 334-344.

[4] L. Liu, J.A. Gardecki, S.K. Nadkarni, J.D. Toussaint, Y. Yagi, B.E. Bouma, G.J Tearney, Imaging the subcellular structure of human coronary atherosclerosis using micro-optical coherence tomography, Nat. Med. 17 (8) (2011) 10101014.

[5] K. Jansen, A.F. van der Steen, H.M. van Beusekom, J.W. Oosterhuis, G. van Soest, Intravascular photoacoustic imaging of human coronary atherosclerosis, Opt. Lett. 36 (5) (2011) 597-599.

[6] B. Wang, J.L. Su, J. Amirian, S.H. Litovsky, R. Smalling, S. Emelianov, Detection of lipid in atherosclerotic vessels using ultrasound-guided spectroscopic intravascular photoacoustic imaging, Opt. Express 18 (5) (2010) 4889-4897.

[7] H.G. Bezerra, M.A. Costa, G. Guagliumi, A.M. Rollins, D.I. Simon, Intracoronary optical coherence tomography: a comprehensive review clinical and research applications, JACC Cardiovasc. Interv. 2 (11) (2009) 1035-1046.

[8] B. Wang A. Karpiouk, D. Yeager, J. Amirian, S. Litovsky, R. Smalling, S. Emelianov, Intravascular photoacoustic imaging of lipid in atherosclerotic plaques in the presence of luminal blood, Opt. Lett. 37 (7) (2012) 1244-1246.

[9] K.J. Ransohoff, J.C. Wu, Advances in cardiovascular molecular imaging for tracking stem cell therapy, Thromb. Haemost. 104 (1) (2010) 13-22.

[10] S.W. Hell, Microscopy and its focal switch, Nat. Methods 6 (1) (2009) 24-32.

[11] G.J. Tserevelakis, D. Soliman, M. Omar, V. Ntziachristos, Hybrid multiphoton and optoacoustic microscope, Opt. Lett. 39 (7) (2014) 1819-1822.

[12] A. Bouwens, T. Bolmont, D. Szlag, C. Berclaz, T. Lasser, Quantitative cerebral blood flow imaging with extended-focus optical coherence microscopy, Opt. Lett. 39 (1) (2014) 37-40.

[13] S. Reitsma, M.G. Oude Egbrink, V.V. Heijnen, R.T. Megens, W. Engels, H. Vink, D.W. Slaaf, M.A. van Zandvoort, Endothelial glycocalyx thickness and plateletvessel wall interactions during atherogenesis, Thromb. Haemost. 106 (5) (2011) 939-946.

[14] M. Drechsler, R.T. Megens, M. van Zandvoort, C. Weber, O. Soehnlein, Hyperlipidemia-triggered neutrophilia promotes early atherosclerosis, Circulation 122 (18) (2010) 1837-1845.

[15] R.T. Megens, S. Vijayan, D. Lievens, Y. Doring, M.A. van Zandvoort, J. Grommes, C. Weber, O. Soehnlein, Presence of luminal neutrophil extracellular traps in atherosclerosis, Thromb. Haemost. 107 (3) (2012) 597-598. 
[16] J. Phipps, Y. Sun, R. Saroufeem, N. Hatami, M.C. Fishbein, L. Marcu, Fluorescence lifetime imaging for the characterization of the biochemical composition of atherosclerotic plaques, J. Biomed. Opt. 16 (9) (2011) 096018.

[17] J. Park, P. Pande, S. Shrestha, F. Clubb, B.E. Applegate, J.A. Jo, Biochemical characterization of atherosclerotic plaques by endogenous multispectral fluorescence lifetime imaging microscopy, Atherosclerosis 220 (2) (2012) 394-401.

[18] M. van Zandvoort, W. Engels, K. Douma, L. Beckers, M. Oude Egbrink, M. Daemen, D.W. Slaaf, Two-photon microscopy for imaging of the (atherosclerotic) vascular wall: a proof of concept study, J. Vasc. Res. 41 (1) (2004) 54-63.

[19] M.D. Cahalan, I. Parker, S.H. Wei, M.J. Miller, Two-photon tissue imaging: seeing the immune system in a fresh light, Nat. Rev. Immunol. 2 (11) (2002) $872-880$.

[20] F. Helmchen, W. Denk, Deep tissue two-photon microscopy, Nat. Methods 2 (12) (2005) 932-940.

[21] R.T. Megens, M.G. Oude Egbrink, J.P. Cleutjens, M.J. Kuijpers, P.H. Schiffers, M. Merkx, D.W. Slaaf, M.A. van Zandvoort, Imaging collagen in intact viable healthy and atherosclerotic arteries using fluorescently labeled CNA35 and two-photon laser scanning microscopy, Mol. Imag. 6 (4) (2007) 247-260.

[22] W. Li, R.G. Nava, A.C. Bribriesco, B.H. Zinselmeyer, J.H. Spahn, A.E. Gelman, A.S. Krupnick, M.J. Miller, D. Kreisel, Intravital 2-photon imaging of leukocyte trafficking in beating heart, J. Clin. Invest. 122 (7) (2012) 2499-2508.

[23] R.T. Megens, S. Reitsma, L. Prinzen, M.G. oude Egbrink, W. Engels, P.J. Leenders, E.J. Brunenberg, K.D. Reesink, B.J. Janssen, B.M. ter Haar Romeny, D. W. Slaaf, M.A. van Zandvoort, In vivo high-resolution structural imaging of large arteries in small rodents using two-photon laser scanning microscopy, J. Biomed. Opt. 15 (1) (2010) 011108.

[24] E. McInnes, Artefacts in histopathology, Comp. Clin. Pathol. 13 (2004) 100108.

[25] W. Denk, J.H. Strickler, W.W. Webb, Two-photon laser scanning fluorescence microscopy, Science 248 (4951) (1990) 73-76.

[26] D.W. Piston, Imaging living cells and tissues by two-photon excitation microscopy, Trends Cell Biol. 9 (2) (1999) 66-69.

[27] K. Konig, Multiphoton microscopy in life sciences, J. Microsc. 200 (Pt 2) (2000) $83-104$.

[28] P. Campagnola, Second harmonic generation imaging microscopy: applications to diseases diagnostics, Anal. Chem. 83 (9) (2011) 3224-3231.

[29] S. Fine, W.P. Hansen, Optical second harmonic generation in biological systems, Appl. Opt. 10 (10) (1971) 2350-2353.

[30] T. Abraham, D. Kayra, B. McManus, A. Scott, Quantitative assessment of forward and backward second harmonic three dimensional images of collagen Type I matrix remodeling in a stimulated cellular environment, J. Struct. Biol. 180 (1) (2012) 17-25.

[31] M. Rehberg, F. Krombach, U. Pohl, S. Dietzel, Label-free 3D visualization of cellular and tissue structures in intact muscle with second and third harmonic generation microscopy, PLoS One 6 (11) (2011) e28237.

[32] S. Dietzel, J. Pircher, A.K. Nekolla, M. Gull, A.W. Brandli, U. Pohl, M. Rehberg, Label-free determination of hemodynamic parameters in the microcirculaton with third harmonic generation microscopy, PLoS One 9 (6) (2014) e99615.

[33] S.J. Remington, Green fluorescent protein: a perspective, Protein Sci. 20 (9) (2011) 1509-1519.

[34] K.W. Kim, A. Vallon-Eberhard, E. Zigmond, J. Farache, E. Shezen, G. Shakhar, A. Ludwig, S.A. Lira, S. Jung, In vivo structure/function and expression analysis of the CX3C chemokine fractalkine, Blood 118 (22) (2011) e156-e167.

[35] P. Rotzius, S. Thams, O. Soehnlein, E. Kenne, C.N. Tseng, N.K. Bjorkstrom, K.J. Malmberg, L. Lindbom, E.E. Eriksson, Distinct infiltration of neutrophils in lesion shoulders in ApoE-/-mice, Am. J. Pathol. 177 (1) (2010) 493-500.

[36] R. Chevre, J.M. Gonzalez-Granado, R.T. Megens, V. Sreeramkumar, C. SilvestreRoig, P. Molina-Sanchez, C. Weber, O. Soehnlein, A. Hidalgo, V. Andres, Highresolution imaging of intravascular atherogenic inflammation in live mice, Circ. Res. 114 (5) (2014) 770-779.

[37] E.K. Koltsova, Z. Garcia, G. Chodaczek, M. Landau, S. McArdle, S.R. Scott, S. von Vietinghoff, E. Galkina, Y.I. Miller, S.T. Acton, K. Ley, Dynamic T cell-APC interactions sustain chronic inflammation in atherosclerosis, J. Clin. Invest. 122 (9) (2012) 3114-3126.

[38] K. Singbartl, J. Thatte, M.L. Smith, K. Wethmar, K. Day, K. Ley, A CD2-green fluorescence protein-transgenic mouse reveals very late antigen-4dependent CD8+ lymphocyte rolling in inflamed venules, J. Immunol. 166 (12) (2001) 7520-7526.

[39] A.J. Iqbal, E. McNeill, T.S. Kapellos, D. Regan-Komito, S. Norman, S. Burd, N. Smart, D.E. Machemer, E. Stylianou, H. McShane, K.M. Channon, A. Chawla, D. R. Greaves, Human CD68 promoter GFP transgenic mice allow analysis of monocyte to macrophage differentiation in vivo, Blood 124 (15) (2014) e33e44.

[40] T. Boulesteix, A.M. Pena, N. Pages, G. Godeau, M.P. Sauviat, E. Beaurepaire, M. C. Schanne-Klein, Micrometer scale ex vivo multiphoton imaging of unstained arterial wall structure, Cytometry A 69 (1) (2006) 20-26.

[41] P. Maffia, G. Grassia, P. Di Meglio, R. Carnuccio, L. Berrino, P. Garside, A. Ianaro, A. Ialenti, Neutralization of interleukin-18 inhibits neointimal formation in a rat model of vascular injury, Circulation 114 (5) (2006) 430-437.

[42] R.T. Megens, S. Reitsma, P.H. Schiffers, R.H. Hilgers, J.G. De Mey, D.W. Slaaf, M. G. oude Egbrink, M.A. van Zandvoort, Two-photon microscopy of vital murine elastic and muscular arteries. Combined structural and functional imaging with subcellular resolution, J. Vasc. Res. 44 (2) (2007) 87-98.
[43] Y. Doring, H. Noels, M. Mandl, B. Kramp, C. Neideck, D. Lievens, M. Drechsler, R.T. Megens, P.V. Tilstam, M. Langer, H. Hartwig, W. Theelen, J.D. Marth, M. Sperandio, O. Soehnlein, C. Weber, Deficiency of the sialyltransferase St3Gal4 reduces Ccl5-mediated myeloid cell recruitment and arrest: short communication, Circ. Res. 114 (6) (2014) 976-981.

[44] M.M. Schmitt, R.T. Megens, A. Zernecke, K. Bidzhekov, N.M. van den Akker, T. Rademakers, M.A. van Zandvoort, T.M. Hackeng, R.R. Koenen, C. Weber, Endothelial junctional adhesion molecule-a guides monocytes into flowdependent predilection sites of atherosclerosis, Circulation 129 (1) (2014) 66-76.

[45] S. Fokong, B. Theek, Z. Wu, P. Koczera, L. Appold, S. Jorge, U. Resch-Genger, M. van Zandvoort, G. Storm, F. Kiessling, T. Lammers, Image-guided, targeted and triggered drug delivery to tumors using polymer-based microbubbles, J. Control Release 163 (1) (2012) 75-81.

[46] L. Prinzen, R.J. Miserus, A. Dirksen, T.M. Hackeng, N. Deckers, N.J. Bitsch, R.T Megens, K. Douma, J.W. Heemskerk, M.E. Kooi, P.M. Frederik, D.W. Slaaf, M.A van Zandvoort, C.P. Reutelingsperger, Optical and magnetic resonance imaging of cell death and platelet activation using annexin a5functionalized quantum dots, Nano Lett. 7 (1) (2007) 93-100.

[47] R.J. Miserus, M.V. Herias, L. Prinzen, M.B. Lobbes, R.J. Van Suylen, A. Dirksen, T. M. Hackeng, J.W. Heemskerk, J.M. van Engelshoven, M.J. Daemen, M.A. van Zandvoort, S. Heeneman, M.E. Kooi, Molecular MRI of early thrombus formation using a bimodal alpha2-antiplasmin-based contrast agent, JACC Cardiovasc. Imaging 2 (8) (2009) 987-996.

[48] M. Nieuwdorp, M.C. Meuwese, H. Vink, J.B. Hoekstra, J.J. Kastelein, E.S. Stroes, The endothelial glycocalyx: a potential barrier between health and vascular disease, Curr. Opin. Lipidol. 16 (5) (2005) 507-511.

[49] S. Reitsma, M.G. oude Egbrink, H. Vink, B.M. van den Berg, V.L. Passos, W. Engels, D.W. Slaaf, M.A. van Zandvoort, Endothelial glycocalyx structure in the intact carotid artery: a two-photon laser scanning microscopy study, J. Vasc. Res. 48 (4) (2011) 297-306.

[50] T.F. Luscher, F.C. Tanner, M.R. Tschudi, G. Noll, Endothelial dysfunction in coronary artery disease, Annu. Rev. Med. 44 (1993) 395-418.

[51] M. Ghosh, N.M. van den Akker, K.A. Wijnands, M. Poeze, C. Weber, L.E. McQuade, M.D. Pluth, S.J. Lippard, M.J. Post, D.G. Molin, M.A. van Zandvoort, Specific visualization of nitric oxide in the vasculature with two-photon microscopy using a copper based fluorescent probe, PLoS One 8 (9) (2013) e75331.

[52] M.H. Lim, D. Xu, S.J. Lippard, Visualization of nitric oxide in living cells by a copper-based fluorescent probe, Nat. Chem. Biol. 2 (7) (2006) 375-380.

[53] C. Napoli, L.J. Ignarro, Nitric oxide and atherosclerosis, Nitric Oxide 5 (2) (2001) 88-97.

[54] C. Weber, H. Noels, Atherosclerosis: current pathogenesis and therapeutic options, Nat. Med. 17 (11) (2011) 1410-1422.

[55] R.R. Koenen, J. Pruessmeyer, O. Soehnlein, L. Fraemohs, A. Zernecke, N. Schwarz, K. Reiss, A. Sarabi, L. Lindbom, T.M. Hackeng, C. Weber, A. Ludwig, Regulated release and functional modulation of junctional adhesion molecule A by disintegrin metalloproteinases, Blood 113 (19) (2009) 4799-4809.

[56] P.E. Szmitko, C.H. Wang, R.D. Weisel, G.A. Jeffries, T.J. Anderson, S. Verma, Biomarkers of vascular disease linking inflammation to endothelial activation: Part II, Circulation 108 (17) (2003) 2041-2048.

[57] C.M. Ballantyne, Y. Abe, Molecular markers for atherosclerosis, J. Cardiovasc. Risk 4 (5-6) (1997) 353-356.

[58] O. Soehnlein, S. Wantha, S. Simsekyilmaz, Y. Doring, R.T. Megens, S.F. Mause, M. Drechsler, R. Smeets, S. Weinandy, F. Schreiber, T. Gries, S. Jockenhoevel, M. Moller, S. Vijayan, M.A. van Zandvoort, B. Agerberth, C.T. Pham, R.L. Gallo, T.M. Hackeng, E.A. Liehn, et al., Neutrophil-derived cathelicidin protects from neointimal hyperplasia, Sci. Transl. Med. 3 (103) (2011) 103 ra198.

[59] Z. Wu, A. Curaj, S. Fokong, E.A. Liehn, C. Weber, T. Lammers, F. Kiessling, M. Zandvoort van, Rhodamine-loaded intercellular adhesion molecule-1targeted microbubbles for dual-modality imaging under controlled shear stresses. Circulation, Cardiovasc. Imaging 6 (6) (2013) 974-981.

[60] A. Curaj, Z. Wu, S. Fokong, E.A. Liehn, C. Weber, A. Burlacu, T. Lammers, M. van Zandvoort, F. Kiessling, Noninvasive molecular ultrasound monitoring of vessel healing after intravascular surgical procedures in a preclinical setup, Arterioscler. Thromb. Vasc. Biol. 35 (6) (2015) 1366-1373.

[61] F.K. Swirski, M. Nahrendorf, Leukocyte behavior in atherosclerosis, myocardial infarction, and heart failure, Science 339 (6116) (2013) 161-166.

[62] S. McArdle, G. Chodaczek, N. Ray, K. Ley, Intravital live cell triggered imaging system reveals monocyte patrolling and macrophage migration in atherosclerotic arteries, J. Biomed. Opt. 20 (2) (2015) 26005.

[63] S. McArdle, E.K. Koltsova, G. Chodaczek, K. Ley, Live cell multiphoton microscopy of atherosclerotic plaques in mouse aortas, in: E. Aikawa (Ed.), Cardiovascular Imaging: Arterial and Aortic Valve Inflammation and Calcification, Vol. I, Springer International Publishing, 2015.

[64] I. Tabas, G. Garcia-Cardena, G.K. Owens, Recent insights into the cellular biology of atherosclerosis, J. Cell Biol. 209 (1) (2015) 13-22.

[65] K. Ley, Y.I. Miller, C.C. Hedrick, Monocyte and macrophage dynamics during atherogenesis, Arterioscler. Thromb. Vasc. Biol. 31 (7) (2011) 1506-1516.

[66] W. Yu, J.C. Braz, A.M. Dutton, P. Prusakov, M. Rekhter, In vivo imaging of atherosclerotic plaques in apolipoprotein E deficient mice using nonlinear microscopy, J. Biomed. Opt. 12 (5) (2007) 054008.

[67] E.A. Dumont, C.P. Reutelingsperger, J.F. Smits, M.J. Daemen, P.A. Doevendans, H.J. Wellens, L. Hofstra, Real-time imaging of apoptotic cell-membrane changes at the single-cell level in the beating murine heart, Nat. Med. 7 (12) (2001) 1352-1355. 
[68] N. Kartalis, L. Loizou, N. Edsborg, R. Segersvard, N. Albiin, Optimising diffusion-weighted MR imaging for demonstrating pancreatic cancer: a comparison of respiratory-triggered, free-breathing and breath-hold techniques, Eur. Radiol. 22 (10) (2012) 2186-2192.

[69] K. Douma, R.T. Megens, M.A. van Zandvoort, Optical molecular imaging of atherosclerosis using nanoparticles: shedding new light on the darkness, Wiley Interdiscip. Rev. Nanomed. Nanobiotechnol. 3 (4) (2011) 376-388.

[70] G.Y. Fan, H. Fujisaki, A. Miyawaki, R.K. Tsay, R.Y. Tsien, M.H. Ellisman, Videorate scanning two-photon excitation fluorescence microscopy and ratio imaging with cameleons, Biophys. J. 76 (5) (1999) 2412-2420.

[71] R.A. Niesner, V. Andresen, M. Gunzer, Intravital two-photon microscopy: focus on speed and time resolved imaging modalities, Immunol. Rev. 221 (2008) 7-25.

[72] R. Kurtz, M. Fricke, J. Kalb, P. Tinnefeld, M. Sauer, Application of multiline two-photon microscopy to functional in vivo imaging, J. Neurosci. Methods 151 (2) (2006) 276-286.

[73] T. Rademakers, K. Douma, T.M. Hackeng, M.J. Post, J.C. Sluimer, M.J. Daemen, E.A. Biessen, S. Heeneman, M.A. van Zandvoort, Plaque-associated vasa vasorum in aged apolipoprotein E-deficient mice exhibit proatherogenic functional features in vivo, Arterioscler. Thromb. Vasc. Biol. 33 (2) (2013) 249-256.

[74] R.A. Boerboom, K.N. Krahn, R.T. Megens, M.A. van Zandvoort, M. Merkx, C.V. Bouten, High resolution imaging of collagen organisation and synthesis using a versatile collagen specific probe, J. Struct. Biol. 159 (3) (2007) 392-399.

[75] I.B. Wilkinson, C.M. McEniery, Arterial stiffness, endothelial function and novel pharmacological approaches, Clin. Exp. Pharmacol. Physiol. 31 (11) (2004) 795-799.

[76] G.A. Plenz, M.C. Deng, H. Robenek, W. Volker, Vascular collagens: spotlight on the role of type VIII collagen in atherogenesis, Atherosclerosis 166 (1) (2003) $1-11$.

[77] E. Adiguzel, P.J. Ahmad, C. Franco, M.P. Bendeck, Collagens in the progression and complications of atherosclerosis, Vasc. Med. 14 (1) (2009) 73-89.

[78] R.T. Megens, M.G. oude Egbrink, M. Merkx, D.W. Slaaf, M.A. van Zandvoort, Two-photon microscopy on vital carotid arteries: imaging the relationship between collagen and inflammatory cells in atherosclerotic plaques, J. Biomed. Opt. 13 (4) (2008) 044022

[79] A. Zoumi, X. Lu, G.S. Kassab, B.J. Tromberg, Imaging coronary artery microstructure using second-harmonic and two-photon fluorescence microscopy, Biophys. J . 87 (4) (2004) 2778-2786.

[80] T.T. Le, I.M. Langohr, M.J. Locker, M. Sturek, J.X. Cheng, Label-free molecular imaging of atherosclerotic lesions using multimodal nonlinear optical microscopy, J. Biomed. Opt. 12 (5) (2007) 054007.

[81] P.J. Campagnola, A.C. Millard, M. Terasaki, P.E. Hoppe, C.J. Malone, W.A Mohler, Three-dimensional high-resolution second-harmonic generation imaging of endogenous structural proteins in biological tissues, Biophys. J . 82 (1 Pt 1) (2002) 493-508.

[82] H.C. Stary, A.B. Chandler, R.E. Dinsmore, V. Fuster, S. Glagov, W. Insull Jr., M.E. Rosenfeld, C.J. Schwartz, W.D. Wagner, R.W. Wissler, A definition of advanced types of atherosclerotic lesions and a histological classification of atherosclerosis. A report from the Committee on Vascular Lesions of the Council on Arteriosclerosis, American Heart Association, Circulation 92 (5) (1995) 1355-1374.

[83] H.M. Sanders, M. Iafisco, E.M. Pouget, P.H. Bomans, F. Nudelman, G. Falini, G. de With, M. Merkx, G.J. Strijkers, K. Nicolay, N.A. Sommerdijk, The binding of CNA35 contrast agents to collagen fibrils, Chem. Commun. 47 (5) (2011) 1503-1505.

[84] M. Sirol, J.G. Aguinaldo, P.B. Graham, R. Weisskoff, R. Lauffer, G. Mizsei, I. Chereshnev, J.T. Fallon, E. Reis, V. Fuster, J.F. Toussaint, Z.A. Fayad, Fibrintargeted contrast agent for improvement of in vivo acute thrombus detection with magnetic resonance imaging, Atherosclerosis 182 (1) (2005) 79-85.

[85] M.R. Makowski, S.C. Forbes, U. Blume, A. Warley, C.H. Jansen, A. Schuster, A.]. Wiethoff, R.M. Botnar, In vivo assessment of intraplaque and endothelial fibrin in ApoE(-/-) mice by molecular MRI, Atherosclerosis 222 (1) (2012) 4349.

[86] M.B. Lilledahl, O.A. Haugen, C. de Lange Davies, L.O. Svaasand, Characterization of vulnerable plaques by multiphoton microscopy, J. Biomed. Opt. 12 (4) (2007) 044005.

[87] M.R. Makowski, A.J. Wiethoff, U. Blume, F. Cuello, A. Warley, C.H. Jansen, E Nagel, R. Razavi, D.C. Onthank, R.R. Cesati, M.S. Marber, T. Schaeffter, A. Smith, S.P. Robinson, R.M. Botnar, Assessment of atherosclerotic plaque burden with an elastin-specific magnetic resonance contrast agent, Nat. Med. 17 (3) (2011) 383-388.

[88] S. de Jong, L.B. van Middendorp, R.H. Hermans, J.M. de Bakker, M.F Bierhuizen, F.W. Prinzen, H.V. van Rijen, M. Losen, M.A. Vos, M.A. van Zandvoort, Ex vivo and in vivo administration of fluorescent CNA35 specifically marks cardiac fibrosis, Mol. Imag. 13 (2014).

[89] W. Habeler, S. Pouillot, A. Plancheron, M. Puceat, M. Peschanski, C. Monville An in vitro beating heart model for long-term assessment of experimental therapeutics, Cardiovasc. Res. 81 (2) (2009) 253-259.

[90] M.A. Panaro, A. Acquafredda, P. Cavallo, A. Cianciulli, C. Saponaro, V. Mitolo Inflammatory responses in embryonal cardiomyocytes exposed to LPS challenge: an in vitro model of deciphering the effects of LPS on the heart, Curr. Pharm. Des. 16 (7) (2010) 754-765.

[91] A. Buehler, M.A. van Zandvoort, B.J. Stelt, T.M. Hackeng, B.H. Schrans-Stassen, A. Bennaghmouch, L. Hofstra, J.P. Cleutjens, A. Duijvestijn, M.B. Smeets, D.P. de Kleijn, M.J. Post, E.D. de Muinck, CNGR: a novel homing sequence for CD13/APN targeted molecular imaging of murine cardiac angiogenesis in vivo, Arterioscler. Thromb. Vasc. Biol. 26 (12) (2006) 2681-2687.

[92] H. Laeremans, T.M. Hackeng, M.A. van Zandvoort, V.L. Thijssen, B.J. Janssen, H. C. Ottenheijm, J.F. Smits, W.M. Blankesteijn, Blocking of frizzled signaling with a homologous peptide fragment of wnt3a/wnt5a reduces infarct expansion and prevents the development of heart failure after myocardial infarction, Circulation 124 (15) (2011) 1626-1635.

[93] M. Matsumoto-Ida, M. Akao, T. Takeda, M. Kato, T. Kita, Real-time 2-photon imaging of mitochondrial function in perfused rat hearts subjected to ischemia/reperfusion, Circulation 114 (14) (2006) 1497-1503.

[94] M. Rubart, E. Wang, K.W. Dunn, L.J. Field, Two-photon molecular excitation imaging of $\mathrm{Ca} 2+$ transients in Langendorff-perfused mouse hearts, Am. J. Physiol. Cell Physiol. 284 (6) (2003) C1654-C1668.

95] S. de Jong, L.B. van Middendorp, R.H. Hermans, J.M. de Bakker, M.F. Bierhuizen, F.W. Prinzen, H.V. van Rijen, M. Losen, M.A. Vos, M.A. van Zandvoort, Ex vivo and in vivo administration of fluorescent CNA35 specifically marks cardiac fibrosis, Mol. Imag. 13 (2014) 1-9.

[96] B. Chen, C. Zhang, A. Guo, L.S. Song, In situ single photon confocal imaging of cardiomyocyte T-tubule system from Langendorff-perfused hearts, Front. Physiol. 6 (2015) 134.

[97] G.E. Kuhnle, F.H. Leipfinger, A.E. Goetz, Measurement of microhemodynamics in the ventilated rabbit lung by intravital fluorescence microscopy, J. Appl. Physiol. 74 (3) (1993) 1462-1471.

[98] N.D. Kirkpatrick, E. Chung, D.C. Cook, X. Han, G. Gruionu, S. Liao, L.L. Munn, T, P. Padera, D. Fukumura, R.K. Jain, Video-rate resonant scanning multiphoton microscopy: an emerging technique for intravital imaging of the tumor microenvironment, Intravital 1 (1) (2012).

[99] S. Lee, C. Vinegoni, P.F. Feruglio, L. Fexon, R. Gorbatov, M. Pivoravov, A. Sbarbati, M. Nahrendorf, R. Weissleder, Real-time in vivo imaging of the beating mouse heart at microscopic resolution, Nat. Commun. 3 (2012) 1054.

[100] C. Vinegoni, A.D. Aguirre, S. Lee, R. Weissleder, Imaging the beating heart in the mouse using intravital microscopy techniques, Nat. Protoc. 10 (11) (2015) $1802-1819$.

[101] J.A. Rodriguez-Feo, J.P. Sluijter, D.P. de Kleijn, G. Pasterkamp, Modulation of collagen turnover in cardiovascular disease, Curr. Pharm. Des. 11 (19) (2005) 2501-2514.

[102] S. Heeneman, J.P. Cleutjens, B.C. Faber, E.E. Creemers, R.J. van Suylen, E. Lutgens, K.B. Cleutjens, M.J. Daemen, The dynamic extracellular matrix: intervention strategies during heart failure and atherosclerosis, J. Pathol. 200 (4) (2003) 516-525.

[103] S. Katsuda, T. Kaji, Atherosclerosis and extracellular matrix, J. Atherosclerosis Thrombosis 10 (5) (2003) 267-274.

[104] M.R. Tsai, Y.W. Chiu, M.T. Lo, C.K. Sun, Second-harmonic generation imaging of collagen fibers in myocardium for atrial fibrillation diagnosis, J. Biomed. Opt. 15 (2) (2010) 026002.

[105] H.G. Breunig, H. Studier, K. Konig, Multiphoton excitation characteristics of cellular fluorophores of human skin in vivo, Opt. Express 18 (8) (2010) 78577871.

[106] M.J. Koehler, S. Zimmermann, S. Springer, P. Elsner, K. Konig, M. Kaatz, Keratinocyte morphology of human skin evaluated by in vivo multiphoton laser tomography, Skin Res. Technol. 17 (4) (2011) 479-486.

[107] A.M. Lee, H. Wang, Y. Yu, S. Tang, J. Zhao, H. Lui, D.I. McLean, H. Zeng, In vivo video rate multiphoton microscopy imaging of human skin, Opt. Lett. 36 (15) (2011) 2865-2867.

[108] R. Kiesslich, J. Burg, M. Vieth, J. Gnaendiger, M. Enders, P. Delaney, A. Polglase, W. McLaren, D. Janell, S. Thomas, B. Nafe, P.R. Galle, M.F. Neurath, Confocal laser endoscopy for diagnosing intraepithelial neoplasias and colorectal cancer in vivo, Gastroenterology 127 (3) (2004) 706-713.

[109] M. Goetz, A. Hoffman, P.R. Galle, M.F. Neurath, R. Kiesslich, Confocal laser endoscopy: new approach to the early diagnosis of tumors of the esophagus and stomach, Future Oncol. 2 (4) (2006) 469-476.

[110] S. Paramsothy, R.W. Leong, Endoscopy: fluorescein contrast in confocal laser endomicroscopy, Nat. Rev. Gastroenterol. Hepatol. 7 (7) (2010) 366-368.

[111] M.F. Neurath, R. Kiesslich, Molecular detection of CD44v6 on aberrant crypt foci by confocal laser endoscopy, Endoscopy 42 (Suppl. 2) (2010) E314-E315.

[112] L. Thiberville, M. Salaun, S. Lachkar, S. Dominique, S. Moreno-Swirc, C. VeverBizet, G. Bourg-Heckly, Confocal fluorescence endomicroscopy of the human airways, Proc. Am. Thorac. Soc. 6 (5) (2009) 444-449.

[113] K. Konig, A. Ehlers, I. Riemann, S. Schenkl, R. Buckle, M. Kaatz, Clinical twophoton microendoscopy, Microsc. Res. Tech. 70 (5) (2007) 398-402.

[114] L. Fu, A. Jain, H. Xie, C. Cranfield, M. Gu, Nonlinear optical endoscopy based on a double-clad photonic crystal fiber and a MEMS mirror, Opt. Express 14 (3) (2006) 1027-1032.

[115] D.R. Rivera, C.M. Brown, D.G. Ouzounov, I. Pavlova, D. Kobat, W.W. Webb, C. $\mathrm{Xu}$, Compact and flexible raster scanning multiphoton endoscope capable of imaging unstained tissue, Proc. Natl. Acad. Sci. U.S.A. 108 (43) (2011) 1759817603.

[116] P. Kim, M. Puoris'haag, D. Cote, C.P. Lin, S.H. Yun, In vivo confocal and multiphoton microendoscopy, J. Biomed. Opt. 13 (1) (2008) 010501.

[117] M. Chen, C. Xu, W.W. Webb, Endoscope lens with dual fields of view and resolutions for multiphoton imaging, Opt. Lett. 35 (16) (2010) 2735-2737.

[118] M. Gu, H. Kang, X. Li, Breaking the diffraction-limited resolution barrier in fiber-optical two-photon fluorescence endoscopy by an azimuthallypolarized beam, Sci. Rep. 4 (2014) 3627. 